\title{
Identification of breast cancer patients with a high risk of developing brain metastases: a single-institutional retrospective analysis
}

Volker Rudat ${ }^{1 *}$, Hamdan El-Sweilmeen ${ }^{2}$, Iris Brune-Erber ${ }^{3}$, Alaa Ahmad Nour ${ }^{1}$, Nidal Almasri ${ }^{4}$, Saleh Altuwaijri ${ }^{5}$ and Elias Fadel ${ }^{2}$

\begin{abstract}
Background: The objective of this study was to identify breast cancer patients with a high risk of developing brain metastases who may benefit from pre-emptive medical intervention.

Methods: Medical records of 352 breast cancer patients with local or locoregional disease at diagnosis were retrospectively analysed. The brain metastasis-free survival was estimated using the Kaplan-Meier method and patient groups were compared using the log rank test. The simultaneous relationship of multiple prognostic factors was assessed using Cox's proportional hazard regression analysis. The Fisher exact test was used to test the difference of proportions for statistical significance.

Results: On univariate analysis, statistically highly significant unfavourable risk factors for the brain metastasis-free survival were negative ER status, negative PR status, and triple negative tumor subtype. Young age at diagnosis ( $\leq 35$ years) and advanced disease stage were not statistically significant $(p=0.10)$. On multivariate analysis, the only independent significant factor was the ER status (negative ER status; hazard radio ( $95 \%$ confidence interval), 5.1 (1.8-14.6); $p=0.003)$. In the subgroup of 168 patients with a minimum follow-up of 24 months, 49 patients developed extracranial metastases as first metastatic event. Of those, 7 of 15 (46.6\%) with a negative ER status developed brain metastases compared to 5 of $34(14.7 \%)$ with a positive ER status (Fisher exact test, $p=0.03$ ). The median time interval (minimum-maximum) between the diagnosis of extracranial and brain metastases was 7.5 months (1-30 months).

Conclusions: Breast cancer patients with extracranial metastasis and negative ER status exhibited an almost 50\% risk of developing brain metastasis during their course of disease. Future studies are highly desired to evaluate the efficacy of pre-emptive medical intervention such as prophylactic treatment or diagnostic screening for high risk breast cancer patients.
\end{abstract}

Keywords: Breast cancer, Brain metastasis, Progesterone receptor negative breast cancer

\section{Background}

The incidence of brain metastases in breast cancer is about $5 \%[1,2]$. While patients with early breast cancer rarely develop brain metastases, symptomatic brain metastases are diagnosed in $10 \%$ to $16 \%$ of patients with metastatic breast cancer $[1,3,4]$. Advances in systemic treatment have substantially improved the overall survival of

\footnotetext{
* Correspondence: vrudat@saadmedical.com

'Department of Radiation Oncology, Saad Specialist Hospital, P.O. Box 30353, Al Khobar 31952, Saudi Arabia

Full list of author information is available at the end of the article
}

advanced breast cancer patients [5,6], and brain metastases are emerging as an important sanctuary site. An increasing proportion of patients have been observed suffering from symptomatic brain metastases often at a time when their extracranial disease is apparently under control [5,7]. The survival of patients with symptomatic multiple brain metastases is poor even after palliative whole brain irradiation [8,9], and better in patients with brain oligometastases where surgical resection or stereotactic radiotherapy can be applied [10-13].

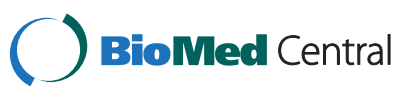


The identification of breast cancer patients with a high risk of developing brain metastases would enable preemptive intervention such as prophylactic treatment or diagnostic screening with the potential to improve the outcome.

Reported risk factors for brain metastases in breast cancer patients include young age at first diagnosis, presence of lung metastases, short disease-free survival, ER negative tumors, triple-negative tumor subtype, HER2 overexpression and BRCA1 phenotype [1,5,14-19].

The objective of this study was to identify a subgroup of breast cancer patients with a high risk of developing brain metastases who may benefit from pre-emptive medical intervention.

\section{Methods}

Medical records were retrospectively reviewed of female breast cancer patients who consulted Saad Specialist Hospital between 2006 and 2013. Eligibility criteria for the analysis were histologically confirmed diagnosis of invasive breast cancer. Patients with distant metastases, synchronous, or metachronous cancer at diagnosis were excluded from the analysis. Staging procedures included complete history and physical examination, laboratory assessments, and diagnostic bilateral mammogram. Where indicated, ultrasonography of the breast and abdomen, chest radiograph, and radionuclide bone scan were performed. Selected patients received magnetic resonance imaging (MRI) of the breast, computerized tomography (CT), or positron emission tomography computed tomography (PET-CT). Patients were presented and discussed in an interdisciplinary Tumor Board Meeting, and a treatment recommendation was generated in accordance with the guidelines of the National Comprehensive Cancer Network (NCCN). Breast conserving surgery (BCS) consisted of wide local excision or lumpectomy and axillary dissection or sentinel lymph node biopsy in selected patients. After modified radical mastectomy, in selected patients breast reconstruction with TRAM-flap was performed. Surgery was followed by chemotherapy and hormonal therapy where indicated. Dependent on the T status, $\mathrm{N}$ status, hormone receptor status, age ( $\leq 35$ years versus $>35$ years), and menopausal status, four cycles of Adriamycin/Cyclophosphamide (AC) or six cycles of Cyclophosphamide/Methotrexate/5-FU (CMF) were prescribed for node negative patients, and four cycles of AC followed by four cycles of paclitaxel or, alternatively, three cycles of 5-FU/epirubicin/cyclophosphamide (FEC) followed by three cycles of docetaxel for node positive patients. Endocrine therapy using tamoxifen or aromatase inhibitors was prescribed where indicated. Trastuzumab was added according to the HER2 status and prescribed for at least one year. Triple negative tumor subtype patients were usually treated with four cycles of AC followed by four cycles of paclitaxel. In selected patients neoadjuvant chemotherapy was applied. Postoperative radiotherapy was performed in all patients after BCS. A total dose of 50.4 Gy in 28 fractions was prescribed, followed by a boost of $10 \mathrm{~Gy}$ in 5 fractions in all patients younger than 50 years. Postmastectomy radiotherapy of the chest wall was given in patients with at least one positive locoregional lymph node. The prescribed dose was $50 \mathrm{~Gy}$ in 25 fractions. Usually opposed tangential beam techniques using three-dimensionally planned conformal radiotherapy (3DCRT) or intensity modulated radiotherapy (IMRT) were applied for the treatment of the whole breast or the chest wall [20]. Follow-up examinations were scheduled every three months in the first year, then every six months for 4 years. PET-CT was performed in many patients during the follow-up. Symptomatic brain metastases were diagnosed by imaging (usually MRI). Breast cancer was classified according to the International Union Against Cancer (UICC), with group clinical and pathological staging according to the American Joint Committee on Cancer (AJCC, 6th edition). Data were entered into a computerized database (MS Access 2010) and analysed using a statistical software package (Statistica 12). This study was approved by the local Institutional Review Board "Institutional Review Board - Saad Specialist Hospital (Registration number: H-05-KH-001, King Abdul-Aziz City of Science and Technology - KACST)" and performed in compliance with the Helsinki Declaration.

\section{Immunohistochemistry}

Sections with a thickness of four $\mu \mathrm{m}$ were cut from paraffin blocks and used for immunohistochemical staining using the iVIEW DAB detection kit on BenchMark autostainer (Ventana, Tucson, AZ, USA). The clones of antibodies SP1, 1E2, and 4B5 were used to evaluate the ER-a, PR, and HER2 status. The Allred scoring system was used to assess the ER and PR status [21]. In summary, a total Allred score was obtained by the summation of proportion score (PS) and intensity score (IS). PS is assigned depending on the proportion of positive cells $(0=$ none; $1<1 \%$; $2=1 \%-<1 / 10 ; 3=1 / 10-<1 / 3 ; 4=1 / 3-<2 / 3 ; 5=2 / 3)$, IS ( 0 =none; 1 = weak; 2 = intermediate; 3 =strong). A total score of 3 or more was considered as positive; scores 0 and 1 and 2 were considered negative. The American Society of Clinical Oncology/College of American Pathologists (ASCO/CAP) guideline recommendations were used to evaluate the HER2 status [22]. Briefly, score 0 indicates no staining in invasive tumor cells. Score +1 indicates weak incomplete membrane staining in any proportion of invasive tumor cells or weak complete membrane staining in $<10 \%$ of cells. Score +2 indicates complete membrane staining in nonuniform or weak but with obvious circumferential distribution in $=10 \%$ of cells, or intense complete membrane staining in $=30 \%$ of 
tumor cells. Score +3 indicates uniform intense membrane staining of $>30 \%$ of invasive tumor cells. Scores 0 and +1 were considered negative; +2 equivocal; and +3 positive. Gene expression profiling studies have shown that immunohistochemistry of paraffin sections is a reliable surrogate for molecular classification of invasive breast cancers [23-28]. Based on this finding, patients of this study were categorized as follows: luminal $\mathrm{A}(\mathrm{ER}+, \mathrm{PR}+$, HER2-), luminal B (ER + and/or PR+, HER2+), HER2 overexpressing (ER-, PR-, HER2+), and triple negative (ER-, PR-, HER2-).

\section{Statistical analysis}

The brain metastasis-free survival was estimated using the Kaplan-Meier method, and patient groups were compared using the log rank test. The brain metastasisfree survival was defined as the time between diagnosis of breast cancer and the detection of brain metastases. Patients who have not developed brain metastases were censored at the time of their last follow-up. The simultaneous relationship of multiple prognostic factors on the brain metastasis-free survival was assessed using Cox's proportional hazard regression analysis. The regression coefficients were estimated by the maximum likelihood method, and model selection was performed by a stepwise strategy using the likelihood ratio test. The Fisher exact test and the Mann-Whitney $U$ test were used to test the difference between patient groups for statistical significance. A 5\% significance level was used and all tests are two-sided.

\section{Results}

Three hundred and fifty-two patients were analyzed in this study. The median follow-up time of the censored patients was 19.5 months (3-72 months). Eight patients died during the follow-up. The treatment of the patients consisted of mastectomy in 203 patients (57.7\%), breast conserving surgery in 139 patients (39.5\%), and nonsurgical treatment in 10 patients (2.8\%). As expected, compared to what is generally reported in the United States and Europe the patients of this study were diagnosed at a strikingly younger age and more advanced stage of the disease (Table 1) [29]. The median age (minimum-maximum) at diagnosis was 48 years (22-94 years) and the median body mass index (minimum-maximum) 29.9 (17.7-66.4) [30].

On univariate analysis, the ER status (Figure 1), the PR status, and the tumor subtype (Figure 2) had a statistically highly significant impact on the brain metastasis-free survival (Table 1). A closer look at the tumor subtype revealed that the triple negative receptor status had a significantly adverse impact on the brain metastasisfree survival (log rank test, $\mathrm{p}<0.01$ ) compared to the combined subtypes luminal $\mathrm{A}$, luminal $\mathrm{B}$ and HER2 overexpressing. Young age at diagnosis ( $\leq 35$ years) and disease stage showed no statistically significant impact $(\mathrm{p}=0.10)$. On multivariate analysis, the only independent significant factor on the brain metastasis-free survival was the ER status (negative ER status, hazard radio (95\% confidence interval), 5.1 (1.8-14.6); $\mathrm{p}=0.003)$. Of 109 patients with a negative ER status 11 developed brain metastasis during the follow-up period and of 238 ER positive patients five.

In the subgroup of patients with a minimum follow-up time of 24 months of the censored patients, 16 of 168 patients (9.5\%) developed brain metastasis. Of 49 patients with extracranial metastases at first metastatic event $12(24.4 \%)$ later developed brain metastases. The median time interval (minimum-maximum) between the diagnosis of extracranial and brain metastases was 7.5 months (1-30 months). In one patient brain metastases and extracranial metastases were detected at the same time, and three patients developed brain metastases as the first or only distant metastasis. Of 15 patients with extracranial metastases and a negative ER status seven (46.6\%) developed brain metastases and of 34 patients with a positive ER status five (14.7\%). The difference between the above proportions is statistically significant (Fisher exact test, $\mathrm{p}=0.03$ ). The median time interval between the diagnosis of extracranial and brain metastasis of ER negative patients was 5 months (1-11 months) and 18 months (3-30 months) for ER positive patients (Mann-Whitney $\mathrm{U}$ test; $\mathrm{p}=0.07$ ).

\section{Discussion}

In our retrospective study breast cancer patients with extracranial metastasis and negative ER status exhibited a $46.6 \%$ risk of developing brain metastasis during the course of their disease. For this patient group pre-emptive medical intervention such as prophylactic treatment or diagnostic screening may be of benefit.

The most promising pre-emptive medical intervention to improve the outcome may be prophylactic cranial irradiation. Autopsy studies have shown a high frequency of occult brain metastasis in patients with metastatic breast cancer [3,31]. Once brain metastases are diagnosed the survival is usually poor. Reported median survival rates of breast cancer patients with brain metastasis are usually in the range of 3 to 8 months $[9,14,16,17,32]$. Prophylactic cranial irradiation has been shown to effectively reduce the frequency of brain metastases and to improve the survival in lung cancer [33-35]. In a study of extensive small cell lung cancer, prophylactic cranial irradiation reduced the frequency of brain metastasis from $40.4 \%$ to $14.6 \%$ ( $\mathrm{p}<0.001)$ and improved the survival rate from $13.3 \%$ to $27.1 \%$ one year after randomization [36]. The total radiation dose required for effective prophylactic whole brain irradiation is 
Table 1 Univariate analysis (Kaplan-Meier method) of possible factors associated with the development of brain metastasis of non-metastatic breast cancer patients at diagnosis

\begin{tabular}{|c|c|c|c|c|c|c|}
\hline Characteristics & $\mathbf{n}$ & $\%$ & 3-year brain metastasis-free survival & $-95 \% \mathrm{Cl}$ & $+95 \% \mathrm{Cl}$ & p-value* \\
\hline Age (years) & & & & & & 0.10 \\
\hline$\leq 35$ & 36 & 10.3 & 0.87 & 0.74 & 1.00 & \\
\hline$>35$ & 316 & 89.7 & 0.95 & 0.92 & 0.99 & \\
\hline Menopausal status & & & & & & 0.33 \\
\hline Pre-menopausal & 165 & 47.0 & 0.95 & 0.91 & 0.99 & \\
\hline Post-menopausal & 187 & 53.0 & 0.94 & 0.88 & 0.99 & \\
\hline Body Mass Index & & & & & & 0.88 \\
\hline$<25$ & 60 & 17.1 & 0.95 & 0.88 & 1.00 & \\
\hline $25-29$ & 118 & 33.6 & 0.96 & 0.91 & 1.00 & \\
\hline$\geq 30$ & 174 & 49.3 & 0.93 & 0.88 & 0.99 & \\
\hline T stage & & & & & & 0.19 \\
\hline $0-2$ & 200 & 56.7 & 0.96 & 0.92 & 1.00 & \\
\hline $3-4$ & 152 & 43.3 & 0.93 & 0.87 & 0.99 & \\
\hline N stage & & & & & & 0.19 \\
\hline $0-1$ & 253 & 72.1 & 0.95 & 0.91 & 0.99 & \\
\hline $2-3$ & 99 & 27.9 & 0.93 & 0.88 & 0.99 & \\
\hline Stage & & & & & & 0.10 \\
\hline Localized & 133 & 37.9 & 0.95 & 0.89 & 1.00 & \\
\hline Regional & 219 & 62.1 & 0.94 & 0.90 & 0.98 & \\
\hline ER status & & & & & & $<0.001$ \\
\hline Positive & 243 & 69.2 & 0.99 & 0.98 & 1.00 & \\
\hline Negative & 109 & 30.8 & 0.84 & 0.74 & 0.94 & \\
\hline PR status & & & & & & 0.01 \\
\hline Positive & 216 & 61.5 & 0.99 & 0.96 & 1.00 & \\
\hline Negative & 136 & 38.5 & 0.88 & 0.80 & 0.95 & \\
\hline HER2 status & & & & & & 0.31 \\
\hline Positive & 88 & 25.1 & 0.98 & 0.95 & 1.00 & \\
\hline Negative & 264 & 74.9 & 0.93 & 0.89 & 0.98 & \\
\hline Tumor subtype & & & & & & $<0.001$ \\
\hline Triple negative & 63 & 17.7 & 0.78 & 0.64 & 0.93 & \\
\hline Her2 overexpressing & 35 & 10.0 & 0.96 & 0.88 & 1.00 & \\
\hline Luminal A & 201 & 57.3 & 0.98 & 0.95 & 1.00 & \\
\hline Luminal B & 53 & 15.1 & 1.00 & 1.00 & 1.00 & \\
\hline
\end{tabular}

Abbreviation: $95 \% \mathrm{Cl}=95 \%$ confidence interval of the 3-year brain metastasis-free survival; ${ }^{*}=$ log rank test.

lower than that required for therapeutic whole brain irradiation of symptomatic brain metastases [37], and the corresponding toxicity is acceptable. Compared to no prophylactic cranial irradiation, prophylactic cranial irradiation showed a negative impact on verbal memory but no or only minimal impact on global cognitive function or global health status [34,35,38]. Due to lack of supporting data prophylactic cranial irradiation has currently no role in breast cancer treatment [32]. The time to the development of brain metastases varies between the patients and it cannot be excluded that in selected patients the seeding of tumors cells in the brain may occur after a prophylactic whole brain irradiation. Future randomized trials are highly desired to evaluate the efficacy of prophylactic cranial irradiation in high risk breast cancer patients.

Another promising prophylactic treatment for patients with HER2 positive disease may be lapatinib, a dual tyrosine-kinase inhibitor of EGFR and HER2. Fewer cases with brain involvement at first progression were 


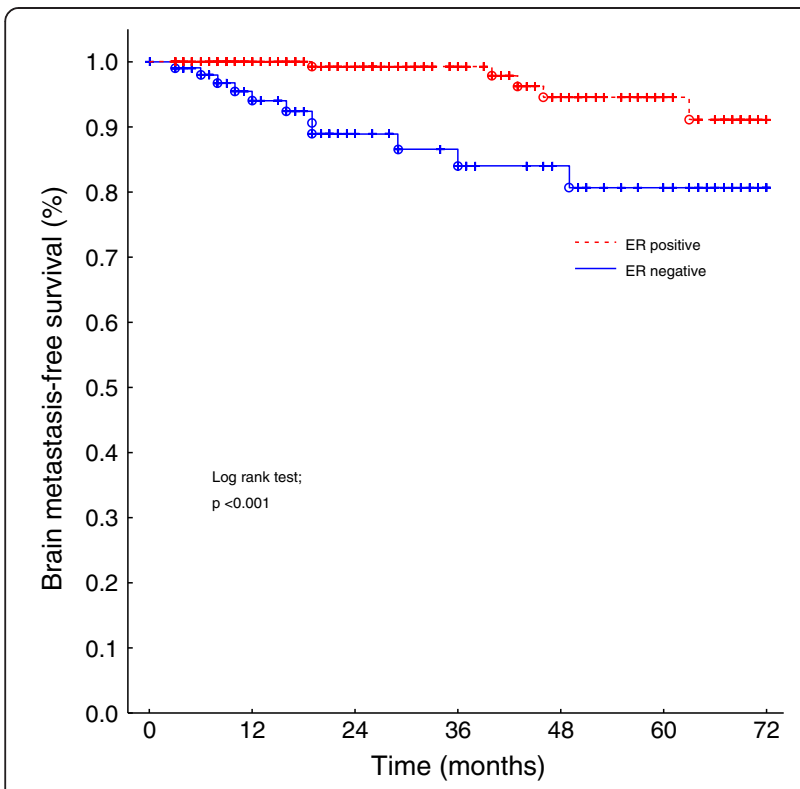

Figure 1 Brain metastases-free survival of breast cancer patients with ER negative versus ER positive tumors.

observed after treatment with lapatinib in a preliminary analysis of a randomized breast cancer study (4 versus 13 , total number of patients 399; $\mathrm{p}=0.045$ ) [39]. Lapatinib plus capecitabine has also shown activity as first-line treatment of brain metastases from HER2-positive breast cancer in a phase II study [40].

The value of diagnostic screening for brain metastases of breast cancer patients is unclear. Patients with single metastasis appear to have a significant longer survival than

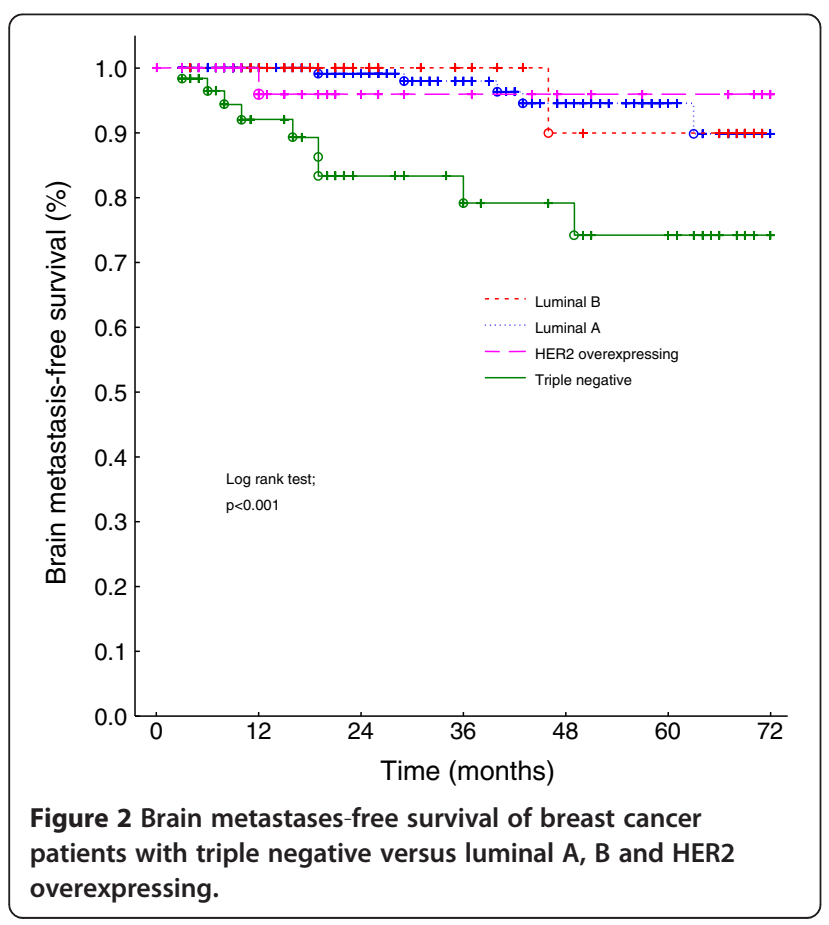

those with multiple metastases [41], and with surgery and stereotactic radiotherapy effective treatment options are available for patients with brain oligometastases. However, early detection of brain metastases has not yet been shown to improve survival $[42,43]$.

The biology underlying the development of brain metastases from breast cancer is only partially understood. The hormone receptor status appears to be associated with the development of brain metastasis as well as with the control of extracranial disease. In addition, it has been shown that the hormonal receptor status is associated with the risk of recurrence of brain metastases after radiosurgery [44]. However, there is a body of evidence suggesting that interactions of metastatic tumour cells with the blood brain barrier and brain microenvironment are also involved in the colonization process [45].

In our study, unfavourable prognostic factors for the brain metastasis-free survival on univariate analysis included negative ER status, negative PR status, triple negative tumor subtype, young age at diagnosis of breast cancer and advanced stage of disease. No high risk group could be defined using these factors for non-metastatic women at diagnosis that would clinically justify preemptive medical intervention.

Our results are in good agreement with other reports from the literature. Evans et al. retrospectively analysed 219 breast cancer patients who had died with metastatic disease [17]. The development of brain metastases was significantly related to young age and to a negative ER status. By combining age and ER status (age under 50 years and negative ER status) the authors were able to identify a group of women with a 53\% risk of developing brain metastasis. The brain metastases commonly occurred after a good response of liver or lung metastases to chemotherapy, and were often the only site of disease progression. The median time between extracranial metastatic presentation and the development of brain metastases was also very similar in the compared studies (6-9 months; our study, 7.5 months).

Berghoff et al. analysed 213 breast cancer patients with brain metastases [14]. The time interval between the diagnosis of extracranial metastases until diagnosis of brain metastases was significantly different between breast cancer subtypes. Triple negative tumors showed the shortest median time interval (14 months) followed by HER 2 positive (18 months) and luminal tumors (34 months). A subgroup analysis showed that patients with a positive ER/HER2 status had a significantly longer time interval compared to ER negative/HER2 positive disease (26 versus 15 months). The authors concluded that patients with triple negative as well as patients with ER negative/HER2 positive disease are at highest risk for developing brain metastases early during their course of disease. 
In agreement with our study, a negative hormone receptor status has been identified as significant unfavourable factor for the probability of developing brain metastases in a study of 215 metastatic breast cancer patients [18].

Limitations of our study are related to the retrospective study design and moderate patient numbers. The observed lack of a statistically significant impact of a young age at diagnosis and advanced disease stage on the brain metastasis-free survival $(p=0.10)$ may be explained by a possible insufficient statistical power of our study. A selection bias cannot be fully excluded and results should be confirmed by future prospective studies.

\section{Conclusions}

In conclusion, breast cancer patients with extracranial metastasis and negative ER status exhibited an almost $50 \%$ risk of developing brain metastasis during their course of disease. Future studies are highly desired to evaluate the efficacy of pre-emptive medical intervention such as prophylactic treatment or diagnostic screening for high risk breast cancer patients.

\section{Abbreviations}

BCS: Breast conserving surgery; BMI: Body mass index; EGFR: Epidermal Growth Factor Receptor; ER: Estrogen receptor; HER2: Human epidermal growth factor receptor 2; PR: Progesterone receptor.

\section{Competing interests}

The authors declare that they have no competing interests.

\section{Authors' contributions}

HS, IB-E, AAN, NA, SA, EF, and VR participated in the acquisition of the data, interpretation of the data and drafting of the manuscript. VR initialized and designed the study and performed the statistical analysis. All authors read and approved the final manuscript.

\section{Acknowledgment}

We acknowledge funding and support of this work by the SAAD Research \& Development Center, Saad Specialist Hospital, and King Abdulaziz City of Science and Technology (KACST) (grant TSCR: 33-837). The views expressed in this publication are those of the authors.

\section{Author details}

${ }^{1}$ Department of Radiation Oncology, Saad Specialist Hospital, P.O. Box 30353, Al Khobar 31952, Saudi Arabia. 'Department of Haematology and Oncology, Saad Specialist Hospital, P.O. Box 30353, Al Khobar 31952, Saudi Arabia. ${ }^{3}$ Department of Surgery, Saad Specialist Hospital, P.O. Box 30353, Al Khobar 31952, Saudi Arabia. ${ }^{4}$ Department of Pathology, Saad Specialist Hospital, P.O. Box 30353, Al Khobar 31952, Saudi Arabia. ${ }^{5}$ SAAD Research \& Development Center, Saad Specialist Hospital, P.O. Box 30353, Al Khobar 31952, Saudi Arabia.

Received: 31 July 2013 Accepted: 22 April 2014

Published: 24 April 2014

\section{References}

1. Barnholtz-Sloan JS, Sloan AE, Davis FG, Vigneau FD, Lai P, Sawaya RE: Incidence proportions of brain metastases in patients diagnosed (1973 to 2001) in the Metropolitan Detroit Cancer Surveillance System. J Clin Oncol 2004, 22(14):2865-2872.

2. Schouten $L J$, Rutten J, Huveneers HA, Twijnstra A: Incidence of brain metastases in a cohort of patients with carcinoma of the breast, colon, kidney, and lung and melanoma. Cancer 2002, 94(10):2698-2705.
3. Tsukada Y, Fouad A, Pickren JW, Lane WW: Central nervous system metastasis from breast carcinoma. Autopsy study Cancer 1983, 52(12):2349-2354.

4. Lin NU, Bellon JR, Winer EP: CNS metastases in breast cancer. J Clin Oncol 2004, 22(17):3608-3617.

5. Lin NU, Winer EP: Brain metastases: the HER2 paradigm. Clin Cancer Res an official j Am Assoc Cancer Res 2007, 13(6):1648-1655.

6. Kiely BE, Soon YY, Tattersall MH, Stockler MR: How long have I got? Estimating typical, best-case, and worst-case scenarios for patients starting first-line chemotherapy for metastatic breast cancer: a systematic review of recent randomized trials. J Clin Oncol official j Am Soc Clinical Oncol 2011, 29(4):456-463.

7. Larsen PB, Kumler I, Nielsen DL: A systematic review of trastuzumab and lapatinib in the treatment of women with brain metastases from HER2-positive breast cancer. Cancer Treatment Reviews 2013, 39(7):720-727.

8. Tsao MN, Lloyd N, Wong RK, Chow E, Rakovitch E, Laperriere N, Xu W, Sahgal A: Whole brain radiotherapy for the treatment of newly diagnosed multiple brain metastases. Cochrane Database Syst Rev 2012, 4, CD003869.

9. Fokstuen T, Wilking N, Rutqvist LE, Wolke J, Liedberg A, Signomklao T, Fernberg JO: Radiation therapy in the management of brain metastases from breast cancer. Breast Cancer Res Treat 2000, 62(3):211-216.

10. Amendola BE, Wolf AL, Coy SR, Amendola M, Bloch L: Gamma knife radiosurgery in the treatment of patients with single and multiple brain metastases from carcinoma of the breast. Cancer j (Sudbury, Mass) 2000, 6(2):88-92.

11. Lederman G, Wronski M, Fine M: Fractionated radiosurgery for brain metastases in 43 patients with breast carcinoma. Breast Cancer Res Treat 2001, 65(2):145-154

12. Matsunaga S, Shuto T, Kawahara N, Suenaga J, Inomori S, Fujino H: Gamma Knife surgery for metastatic brain tumors from primary breast cancer: treatment indication based on number of tumors and breast cancer phenotype. J Neurosurg 2010, 113(Suppl):65-72.

13. Wronski M, Arbit E, McCormick B: Surgical treatment of 70 patients with brain metastases from breast carcinoma. Cancer 1997, 80(9):1746-1754.

14. Berghoff A, Bago-Horvath Z, De Vries C, Dubsky P, Pluschnig U, Rudas M, Rottenfusser A, Knauer M, Eiter H, Fitzal F, Dieckmann K, Mader RM, Gnant M, Zielinski CC, Steger GG, Preusser M, Bartsch R: Brain metastases free survival differs between breast cancer subtypes. Br J Cancer 2012, 106(3):440-446.

15. Weil RJ, Palmieri DC, Bronder JL, Stark AM, Steeg PS: Breast cancer metastasis to the central nervous system. Am J Pathol 2005, 167(4):913-920.

16. Gonzalez-Angulo AM, Cristofanilli M, Strom EA, Buzdar AU, Kau SW, Broglio KR, Smith TL, Hortobagyi GN: Central nervous system metastases in patients with high-risk breast carcinoma after multimodality treatment. Cancer 2004, 101(8):1760-1766.

17. Evans AJ, James JJ, Cornford EJ, Chan SY, Burrell HC, Pinder SE, Gutteridge E, Robertson JF, Hornbuckle J, Cheung KL: Brain metastases from breast cancer: identification of a high-risk group. Clin Oncol (R Coll Radiol (G B)) 2004, 16(5):345-349.

18. Slimane K, Andre F, Delaloge S, Dunant A, Perez A, Grenier J, Massard C, Spielmann M: Risk factors for brain relapse in patients with metastatic breast cancer. Ann Oncol 2004, 15(11):1640-1644.

19. Albiges L, Andre F, Balleyguier C, Gomez-Abuin G, Chompret A, Delaloge S: Spectrum of breast cancer metastasis in BRCA1 mutation carriers: highly increased incidence of brain metastases. Ann Oncol official j Eur Soc Med Oncol/ESMO 2005, 16(11):1846-1847.

20. Rudat V, Alaradi AA, Mohamed A, Ai-Yahya K, Altuwaiji S: Tangential beam IMRT versus tangential beam 3D-CRT of the chest wall in postmastectomy breast cancer patients: a dosimetric comparison. Radiat Oncol (Lond, Engl) 2011, 6:26.

21. Harvey JM, Clark GM, Osborne CK, Allred DC: Estrogen receptor status by immunohistochemistry is superior to the ligand-binding assay for predicting response to adjuvant endocrine therapy in breast cancer. J Clin Oncol official j Am Soc Clin Oncol 1999, 17(5):1474-1481.

22. Wolff AC, Hammond ME, Schwartz JN, Hagerty KL, Allred DC, Cote RJ, Dowsett M, Fitzgibbons PL, Hanna WM, Langer A, McShane LM, Paik S, Pegram MD, Perez EA, Press MF, Rhodes A, Sturgeon C, Taube SE, Tubbs R, Vance $\mathrm{GH}$, van de Vijver M, Wheeler TM, Hayes DF: American Society of Clinical Oncology/College of American Pathologists guideline recommendations for human epidermal growth factor receptor 2 testing in breast cancer. Arch Pathol Lab Med 2007, 131(1):18-43. 
23. Nielsen TO, Hsu FD, Jensen $K$, Cheang M, Karaca G, Hu Z, Hernandez-Boussard T, Livasy C, Cowan D, Dressler L, Akslen LA, Ragaz J, Gown AM, Gilks CB, van de Rijn M, Perou CM: Immunohistochemical and clinical characterization of the basal-like subtype of invasive breast carcinoma. Clin Cancer Res 2004, 10(16):5367-5374.

24. Abd El-Rehim DM, Ball G, Pinder SE, Rakha E, Paish C, Robertson JF, Macmillan D, Blamey RW, Ellis IO: High-throughput protein expression analysis using tissue microarray technology of a large well-characterised series identifies biologically distinct classes of breast cancer confirming recent cDNA expression analyses. Int j cancer J int du cancer 2005, 116(3):340-350.

25. Abd El-Rehim DM, Pinder SE, Paish CE, Bell J, Blamey RW, Robertson JF, Nicholson RI, Ellis IO: Expression of luminal and basal cytokeratins in human breast carcinoma. J Pathol 2004, 203(2):661-671.

26. Brenton JD, Carey LA, Ahmed AA, Caldas C: Molecular classification and molecular forecasting of breast cancer: ready for clinical application? J Clin Oncol official j Am Soc Clin Oncol 2005, 23(29):7350-7360.

27. van de Rijn M, Perou CM, Tibshirani $R$, Haas $P$, Kallioniemi O, Kononen J, Torhorst J, Sauter G, Zuber M, Kochli OR, Mross F, Dieterich H, Seitz R, Ross D, Botstein D, Brown P: Expression of cytokeratins 17 and 5 identifies a group of breast carcinomas with poor clinical outcome. Am J Pathol 2002, 161(6):1991-1996.

28. Tamimi RM, Baer HJ, Marotti J, Galan M, Galaburda L, Fu Y, Deitz AC, Connolly JL, Schnitt SJ, Colditz GA, Collins LC: Comparison of molecular phenotypes of ductal carcinoma in situ and invasive breast cancer. Breast Cancer Res: BCR 2008, 10(4):R67.

29. Rudat V, Brune-Erbe I, Noureldin A, Bushnag Z, Almuraikhi N, Altuwaijri S: Epidemiology of breast cancer patients at a tertiary care center in the Eastern Province of Saudi Arabia. Gulf J Oncolog 2012, 1(11):45-49.

30. Rudat V, Birido N, Tuwaijri S, Al-Abbadi MA: Body Mass Index and Breast Cancer Risk: A Retrospective Multi-Institutional Analysis in Saudi Arabia. Adv Breast Cancer Res 2013, 2(1):4

31. Lee YT: Breast carcinoma: pattern of metastasis at autopsy. J Surg Oncol 1983, 23(3):175-180.

32. Saip $P$, Cicin I, Eralp $Y$, Karagol H, Kucucuk $S$, Cosar Alas $R$, Yavuz E, Dincer M, Saglam E, Topuz E: Identification of patients who may benefit from the prophylactic cranial radiotherapy among breast cancer patients with brain metastasis. J Neuro-Oncol 2009, 93(2):243-251.

33. Blanchard $P$, Le Pechoux C: Prophylactic cranial irradiation in lung cancer. Curr Opin Oncol 2010, 22(2):94-101

34. Slotman BJ, Mauer ME, Bottomley A, Faivre-Finn C, Kramer GW, Rankin EM, Snee M, Hatton M, Postmus PE, Collette L, Senan S: Prophylactic cranial irradiation in extensive disease small-cell lung cancer: short-term healthrelated quality of life and patient reported symptoms: results of an international Phase III randomized controlled trial by the EORTC Radiation Oncology and Lung Cancer Groups. J Clin Oncol: official jAm Soc Clin Oncol 2009, 27(1):78-84.

35. Sun A, Bae K, Gore EM, Movsas B, Wong SJ, Meyers CA, Bonner JA, Schild SE, Gaspar LE, Bogart JA, Werner-Wasik M, Choy H: Phase III trial of prophylactic cranial irradiation compared with observation in patients with locally advanced non-small-cell lung cancer: neurocognitive and quality-of-life analysis. J Clin Oncol: official j Am Soc Clin Oncol 2011, 29(3):279-286.

36. Slotman B, Faivre-Finn C, Kramer G, Rankin E, Snee M, Hatton M, Postmus P, Collette L, Musat E, Senan S: Prophylactic cranial irradiation in extensive small-cell lung cancer. N Engl J Med 2007, 357(7):664-672.

37. Le Pechoux C, Dunant A, Senan S, Wolfson A, Quoix E, Faivre-Finn C, Ciuleanu T, Arriagada R, Jones R, Wanders R, Lerouge D, Laplanche A: Standard-dose versus higher-dose prophylactic cranial irradiation $(\mathrm{PCI})$ in patients with limited-stage small-cell lung cancer in complete remission after chemotherapy and thoracic radiotherapy (PCI 99-01, EORTC 2200308004, RTOG 0212, and IFCT 99-01): a randomised clinical trial. Lancet Oncol 2009, 10(5):467-474.

38. Welzel G, Fleckenstein K, Schaefer J, Hermann B, Kraus-Tiefenbacher U, Mai SK Wenz F: Memory function before and after whole brain radiotherapy in patients with and without brain metastases. Int J Radiat Oncol Biol Phys 2008, 72(5):1311-1318

39. Cameron D, Casey M, Press M, Lindquist D, Pienkowski T, Romieu CG, Chan S, Jagiello-Gruszfeld A, Kaufman B, Crown J, Chan A, Campone M, Viens P, Davidson N, Gorbounova V, Raats JI, Skarlos D, Newstat B, Roychowdhury D, Paoletti P, Oliva C, Rubin S, Stein S, Geyer CE: A phase III randomized comparison of lapatinib plus capecitabine versus capecitabine alone in women with advanced breast cancer that has progressed on trastuzumab: updated efficacy and biomarker analyses. Breast Cancer Res Treat 2008, 112(3):533-543.

40. Bachelot T, Romieu G, Campone M, Dieras V, Cropet C, Dalenc F, Jimenez M, Le Rhun E, Pierga JY, Goncalves A, Leheurteur M, Domont J, Gutierrez M, Cure H, Ferrero JM, Labbe-Devilliers C: Lapatinib plus capecitabine in patients with previously untreated brain metastases from HER2-positive metastatic breast cancer (LANDSCAPE): a single-group phase 2 study. Lancet Oncol 2013, 14(1):64-71.

41. Harputluoglu H, Dizdar O, Aksoy S, Kilickap S, Dede DS, Ozisik Y, Guler N, Barista I, Gullu I, Hayran M, Selek U, Cengiz M, Zorlu F, Tekuzman G, Altundag K: Characteristics of breast cancer patients with central nervous system metastases: a single-center experience. J Natl Med Assoc 2008, 100(5):521-526.

42. Niwinska A, Tacikowska M, Murawska M: The effect of early detection of occult brain metastases in HER2-positive breast cancer patients on survival and cause of death. Int J Radiat Oncol Biol Phys 2010, 77(4):1134-1139.

43. Tomasevic ZI, Rakocevic Z, Tomasevic ZM, Milovanovic Z, Inic M, Kolarevic $D$, Lukic $V$, Kovac Z: Incidence of brain metastases in early stage HER2 3+ breast cancer patients; is there a role for brain CT in asymptomatic patients? J BUON: official j Balkan Union of Oncol 2012, 17(2):249-253.

44. Vern-Gross TZ, Lawrence JA, Case LD, McMullen KP, Bourland JD, Metheny-Barlow LJ, Ellis TL, Tatter SB, Shaw EG, Urbanic JJ, Chan MD: Breast cancer subtype affects patterns of failure of brain metastases after treatment with stereotactic radiosurgery. J Neuro-Oncol 2012, 110(3):381-388.

45. Saunus JM, Momeny M, Simpson PT, Lakhani SR, Da Silva L: Molecular aspects of breast cancer metastasis to the brain. Genet res int 2011, 2011:219189.

doi:10.1186/1471-2407-14-289

Cite this article as: Rudat et al:: Identification of breast cancer patients with a high risk of developing brain metastases: a single-institutional retrospective analysis. BMC Cancer 2014 14:289.

\section{Submit your next manuscript to BioMed Central and take full advantage of:}

- Convenient online submission

- Thorough peer review

- No space constraints or color figure charges

- Immediate publication on acceptance

- Inclusion in PubMed, CAS, Scopus and Google Scholar

- Research which is freely available for redistribution

Submit your manuscript at www.biomedcentral.com/submit
C) Biomed Central 